\title{
Role of Escherichia coli heat shock proteins IbpA and IbpB in protection of alcohol dehydrogenase AdhE against heat inactivation in the presence of oxygen
}

\author{
Ewelina Matuszewska ${ }^{1}$, Joanna Kwiatkowska ${ }^{1}$, Elżbieta Ratajczak ${ }^{2}$, Dorota \\ Kuczyńska-Wiśnik ${ }^{1}$ and Ewa Laskowska ${ }^{1 \bowtie}$ \\ ${ }^{1}$ Department of Biochemistry, and ${ }^{2}$ Department of Cellular and Molecular Biology, Faculty of Biotechnology, \\ University of Gdańsk, Gdańsk, Poland
}

Received: 04 August, 2008; revised: 12 January, 2009; accepted: 17 February, 2009 available on-line: 24 February, 2009

\begin{abstract}
Escherichia coli small heat shock proteins $\mathrm{IbpA}$ and $\mathrm{IbpB}$ are molecular chaperones that bind denatured proteins and facilitate their subsequent refolding by the ATP-dependent chaperones DnaK/DnaJ/GrpE and ClpB. In vivo, the lack of IbpA and IbpB proteins results in increased protein aggregation under severe heat stress or delayed removal of aggregated proteins at recovery temperatures. In this report we followed the appearance and removal of aggregated alcohol dehydrogenase, AdhE, in E. coli submitted to heat stress in the presence of oxygen. During prolonged incubation of cells at $50^{\circ} \mathrm{C}$, when AdhE was progressively inactivated, we initially observed aggregation of AdhE and thereafter removal of aggregated AdhE. In contrast to previous studies, the lack of IbpA and IbpB did not influence the formation and removal of AdhE aggregates. However, in $\triangle i b p A B$ cells AdhE was inactivated and oxidized faster than in wild type strain. Our results demonstrate that $\mathrm{IbpA}$ and $\mathrm{IbpB}$ protected AdhE against thermal and oxidative inactivation, providing that the enzyme remained soluble. IbpA and IbpB were dispensable for the processing of irreversibly damaged and aggregated AdhE.
\end{abstract}

Keywords: small heat shock proteins IbpA and $\mathrm{IbpB}$, protein aggregation, protein oxidation, AdhE

\section{INTRODUCTION}

Escherichia coli $\mathrm{IbpA}$ and $\mathrm{IbpB}$ proteins belong to the ubiquitous family of small heat shock proteins (sHsps) whose members are involved in many cellular processes: cell development, cancerogenesis, regulation of apoptosis, rearrangement of the cytoskeleton and protection against various stresses including heat shock (reviewed in Haslbeck et al., 2005; Sun \& MacRae, 2005; Nakamoto \& Vigh, 2007). The common features of sHsps are: low molecular mass, oligomeric structure and the presence of a conserved C-terminal " $\alpha$-crystallin" domain. sHsps form stable complexes with damaged proteins and facilitate refolding of the substrates in cooperation with the ATP-dependent molecular chaperones belonging to the Hsp70 fam- ily (Haslbeck et al., 2005; Nakamoto \& Vigh, 2007). When sHsps are overloaded with non-native substrates in vitro, the sHsp-substrate complexes form insoluble aggregates (Mogk et al., 2003b; Jiao et al., 2005). In E. coli cells submitted to heat stress $\mathrm{IbpAB}$ are present mainly in aggregates of denatured endogenous proteins (Laskowska et al., 1996). In vitro, proteins bound to $\mathrm{IbpA}$ and $\mathrm{IbpB}$ are refolded by the ATP-dependent DnaK chaperone and its cochaperones DnaJ and GrpE. ClpB, the $\mathrm{AAA}^{+}$ family member, which cooperates with the DnaK machinery, increases the efficiency of refolding of polypeptides bound to IbpA and/or IbpB (Veinger et al., 1998; Mogk et al., 2003a; 2003b; Matuszewska et al., 2005). IbpA and $\mathrm{IbpB}$ share $50 \%$ amino-acid homology and interact in vitro, but the nature of their cooperation in the refolding remains elusive

$\square$ Corresponding author: Ewa Laskowska, Department of Biochemistry, University of Gdańsk, Kładki 24, 80-952 Gdańsk, Poland; phone/fax: (48) 58523 6309; e-mail: lasko@biotech.ug.gda.pl

Abbreviations: DNP, 2,4-dinitrophenol; Hsps, heat shock proteins; MCO, metal-catalyzed oxidation; PAGE, polyacrylamide gel electrophoresis; SDS, sodium dodecyl sulfate; wt, wild type. 
(Matuszewska et al., 2005). It has been suggested that $\mathrm{IbpA}$ and $\mathrm{IbpB}$ may exhibit different substrate specifity and the binding of $\mathrm{IbpB}$ to unfolded substrates is IbpA-dependent (Kuczyńska-Wiśnik et al., 2002; Matuszewska et al., 2005).

The lack of IbpA and IbpB proteins results in increased aggregation of denatured proteins in $E$. coli cells under severe heat stress $\left(50^{\circ} \mathrm{C}\right)$ (KuczyńskaWiśnik et al., 2002) or at a lower heat shock temperature $\left(45^{\circ} \mathrm{C}\right)$ in the double mutant $\triangle i b p A B \triangle \operatorname{clp} B$, and in $\triangle i b p A B$ cells with down-regulated DnaK/DnaJ levels (Mogk et al., 2003a). It was also reported that in the $\triangle i b p A B$ strain removal of aggregated proteins is inhibited after a shift from high to recovery temperatures (Kuczyńska-Wiśnik, et al., 2002; Mogk et al., 2003a; Jiao et al., 2005). In this paper we extended in vivo studies focusing on a single natural IbpA and IbpB substrate. We investigated the influence of $\mathrm{IbpA}$ and $\mathrm{IbpB}$ on inactivation and aggregation of alcohol dehydrogenase (AdhE) promoted by heat shock in the presence of oxygen. AdhE is an $\mathrm{Fe}^{2+}$ dependent protein produced at a high level under anaerobic conditions. After a shift of bacteria from anaerobic to aerobic conditions transcription of the adhE gene is significantly reduced and AdhE is irreversibly inactivated by metal-catalyzed oxidation (MCO). In this reaction, $\mathrm{Fe}^{2+}$ reacts with $\mathrm{H}_{2} \mathrm{O}_{2}$ and generates hydroxyl radicals which covalently attack the amino-acid residues near the metal binding site, which results in formation of carbonyl derivatives (Membrillo-Hernandez et al., 2000; Cecarini et al., 2007). Recently, we have demonstrated that IbpA and IbpB protect AdhE against $\mathrm{MCO}$ in vivo and in vitro during oxidative stress induced by copper ions (Matuszewska et al., 2008).

\section{MATERIALS AND METHODS}

Bacterial strains and growth conditions. E. coli MC4100 [araD139 $\Delta$ (lacIPOZYA argF) U169 fla relA rpsL] and its derivative MC4100 $\triangle i b p A B:: \mathrm{cm}$ (Kuczyńska-Wiśnik et al., 2002) were grown anaerobically in plastic tubes filled to the top at $30^{\circ} \mathrm{C}$ (without agitation) in Luria broth (LB) supplemented with $0.2 \%$ glucose. It should be noted that such conditions were not strictly anaerobic, although the availability of oxygen was significantly limited (Eraso \& Weinstock, 1992). At the exponential phase bacteria were exposed to heat stress under aerobic conditions, i.e. the cultures were transferred to flasks and incubated at $50^{\circ} \mathrm{C}$ in a water bath with shaking (200 r.p.m.).

Isolation of protein aggregates. Insoluble protein aggregates were isolated as described previously, with modifications (Kuczyńska-Wiśnik et al., 2002). Briefly, cells were harvested, converted into spheroplasts, lysed by sonication and fractionated by ultracentrifugation in a sucrose density gradient
(1 ml of $60 \%, 1.5 \mathrm{ml}$ of $55 \%, 1.5 \mathrm{ml}$ of $50 \% 1 \mathrm{ml}$ of $45 \%, 1 \mathrm{ml}$ of $40 \%, 1 \mathrm{ml}$ of $35 \%$ and $0.6 \mathrm{ml}$ of $30 \%$, $\mathrm{w} / \mathrm{w}$, sucrose) to separate insoluble protein aggregates (buoyant density of $1.24-1.26 \mathrm{~g} / \mathrm{ml}$ ) from membranes and soluble proteins. Twenty-eight subfractions were collected from the bottom of a tube and analysed for protein concentration according to the method of Bradford (1976).

Detection of protein-bound carbonyl groups. Bacteria were collected, resuspended in $0.5 \mathrm{M}$ Tris/ $\mathrm{HCl}$ buffer ( $\mathrm{pH}$ 6.8) containing 6\% SDS, $10 \mathrm{mM}$ EDTA and lysed at $95^{\circ} \mathrm{C}$ for $5 \mathrm{~min}$. Aliquots of extracts containing equal amounts of total protein were subjected to derivatization with $10 \mathrm{mM}$ 2,4-dinitrophenylhydrazine (DNPH) in $2 \mathrm{M} \mathrm{HCl}$ for $30 \mathrm{~min}$ at room temperature. The samples were neutralized with $2 \mathrm{M} \mathrm{NaOH}$, separated by SDS/PAGE and transferred to a nitrocellulose membrane. Protein-bound 2,4-dinitrophenylhydrazones were detected using anti-2,4-dinitrophenol (DNP) antibodies (Sigma) and ECL Western blotting reagents (Pierce Biotechnology).

AdhE inactivation and refolding assay. AdhE, IbpA, IbpB, DnaK, DnaJ and GrpE proteins were purified as described previously (Matuszewska et al., 2005; 2008). AdhE $(0.4 \mu \mathrm{M})$ was inactivated in buffer C (50 mM Tris/HCl, pH 7.4, $150 \mathrm{mM} \mathrm{KCl}$, $2 \mathrm{mM}$ dithiothreitol, $20 \mathrm{mM} \mathrm{MgCl}$ ) at $50^{\circ} \mathrm{C}$ for 15 $\mathrm{min}$. The refolding was performed in buffer $\mathrm{C}$ supplemented with ATP $(5 \mathrm{mM})$, ATP regeneration system $(10 \mathrm{mM}$ phosphocreatine and $100 \mu \mathrm{g} / \mathrm{ml}$ phosphocreatine kinase) and chaperone proteins $(1.5 \mu \mathrm{M}$ DnaK, $0.12 \mu \mathrm{M}$ DnaJ, $0.15 \mu \mathrm{M}$ GrpE) at $25^{\circ} \mathrm{C}$. AdhE activity was measured spectrophotometrically at 340 $\mathrm{nm}$ in a reaction mixture containing $0.66 \mathrm{mM} \mathrm{NAD}^{+}$, 1.6 $\mathrm{M}$ ethanol and $0.3 \mathrm{M}$ potassium carbonate buffer $\mathrm{pH}$ 10. A unit of enzyme activity is defined as the amount producing one nanomole of NADH per minute (Membrillo-Hernandez et al., 2000).

SDS/PAGE and immunoblotting. Gel electrophoresis and Western blotting were performed according to standard protocols (Sambrook et al., 1989). Immunodetection of proteins was carried out using polyclonal antibodies against AdhE (Matuszewska et al., 2008), anti-rabbit IgG horseradish peroxidaseconjugate (Sigma) and ECL detection reagents (Pierce Biotechnology). Membranes were scanned and analyzed with the 1DScan EX program (Scanalytics).

\section{RESULTS}

IbpA and IbpB inhibit inactivation of AdhE during heat shock in vivo

To study the role of IbpA and IbpB in AdhE protection, we first compared the activity of AdhE 

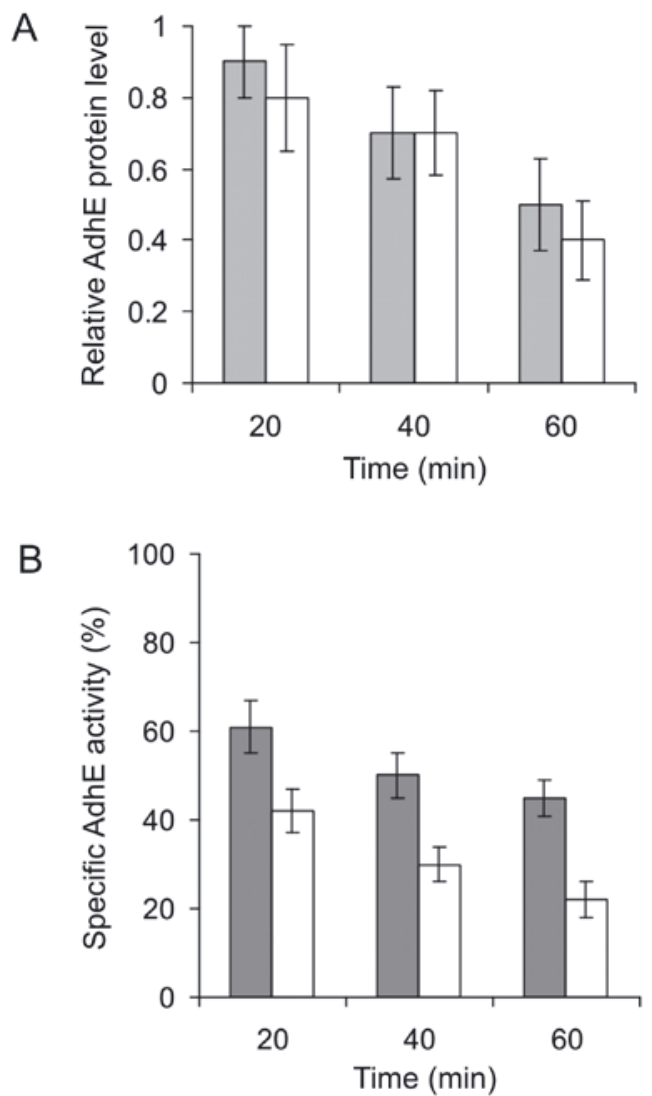

Figure 1. IbpA and IbpB proteins protect AdhE against thermal inactivation in vivo.

A. E. coli wt and $\triangle i b p A B$ strains were grown anaerobically at $30^{\circ} \mathrm{C}$ to an $\mathrm{OD}_{595}$ of 0.3 and then shifted to $50^{\circ} \mathrm{C}$. At the indicated time points, samples containing equal amounts of bacteria were collected, resolved by SDS/PAGE and analyzed by immunoblotting using anti-AdhE antibody. The level of AdhE was estimated by densitometry (wt, grey bars; $\triangle i b p A B$, white bars). B. Specific AdhE activity in wt and $\triangle i b p A B$ cell submitted to heat shock. The data correspond to the means \pm S.D. of three independent experiments.

in wild type (wt) and $\triangle i b p A B E$. coli strains submitted to heat stress. To induce high-level synthesis of AdhE, the cells were grown anaerobically at $30^{\circ} \mathrm{C}$. At the mid-exponential phase the cells were shifted to $50^{\circ} \mathrm{C}$ and incubated under aerobic conditions for $1 \mathrm{~h}$. Since a decrease of AdhE activity might result from denaturation as well as degradation of the enzyme the amount of AdhE protein in bacteria was monitored by Western blotting. After $1 \mathrm{~h}$ at $50^{\circ} \mathrm{C}$ the level of AdhE protein decreased to $50 \%$ and $40 \%$ in wt and in $\triangle i b p A B$ cells, respectively (Fig. 1A). At various time points of the experiment we determined AdhE concentration by Western blotting using serial dilutions of purified AdhE as standards and antiAdhE antibodies (not shown), measured its activity and calculated specific AdhE activity. This approach enabled us to compare the degree of AdhE inactivation in the wt and $\triangle i b p A B$ strains regardless of the rate of AdhE degradation. In non-stressed anaerobic

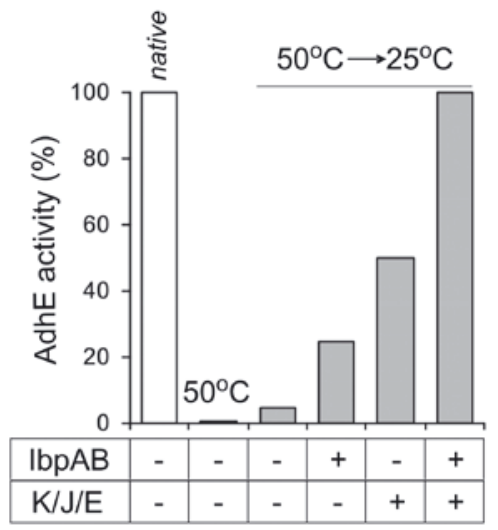

Figure 2. AdhE reactivation by the IbpA-IbpB-DnaK chaperone system.

AdhE $(0.4 \mu \mathrm{M})$ was inactivated in the presence of $2 \mu \mathrm{M}$ $\mathrm{IbpA}$ and $7.8 \mu \mathrm{M} \mathrm{IbpB}$ or alone at $50^{\circ} \mathrm{C}$ for $15 \mathrm{~min}$. After inactivation, the reaction mixtures were supplemented with DnaK $(1.5 \mu \mathrm{M})$, DnaJ $(0.12 \mu \mathrm{M})$ and GrpE $(0.15 \mu \mathrm{M})$. AdhE activity was measured in the samples after $1 \mathrm{~h}$ incubation at $25^{\circ} \mathrm{C}$. Representative results of three independent experiments are shown.

wt and $\triangle i b p A B$ cultures $7500 \pm 300 \mathrm{U} / \mathrm{mg}$ AdhE was detected and set to $100 \%$. We found that after $1 \mathrm{~h}$ of growth at $50^{\circ} \mathrm{C}$ specific AdhE activity decreased to $45 \%$ and $22 \%$ in wt and $\triangle i b p A B$ cells, respectively (Fig. 1B), indicating that IbpA and/or IbpB participate in the protection of AdhE against heat-inactivation.

$\mathrm{IbpA}$ and $\mathrm{IbpB}$ cooperate in the stress management with the ATP-dependent chaperones, therefore we performed in vitro assay to confirm that AdhE can be reactivated by the IbpA-IbpB-DnaKDnaJ-GrpE system (Fig. 2). The amounts of IbpA (2 $\mu \mathrm{M})$, IbpB $(7.8 \mu \mathrm{M})$, DnaK $(1.5 \mu \mathrm{M})$, DnaJ $(0.12 \mu \mathrm{M})$, GrpE $(0.11 \mu \mathrm{M})$ optimal for reactivation, were used according to published data (Matuszewska et al., 2005). AdhE was denatured at $50^{\circ} \mathrm{C}$ for $15 \mathrm{~min}$ in the absence or presence of $\mathrm{IbpA}$ and $\mathrm{IbpB}$ and subsequently the ATP-dependent DnaK/DnaJ/GrpE system was added or not. The efficiency of protection/ refolding was measured after $1 \mathrm{~h}$ incubation at $25^{\circ} \mathrm{C}$. In the presence of IbpA and IbpB alone $25 \%$ of $\mathrm{AdhE}$ activity was restored. When DnaK/DnaJ/GrpE were added after denaturation of AdhE in the absence of $\mathrm{IbpA}$ and $\mathrm{IbpB}$, only $50 \%$ of the enzyme was refolded. Complete refolding was observed when the DnaK system was added to AdhE preincubated with $\mathrm{IbpA}$ and IbpB (Fig. 2). Therefore, IbpA and IbpB increase the efficiency of reactivation of heat-denatured AdhE by the DnaK system.

Lack of IbpA and IbpB proteins does not affect the level of aggregated AdhE under heat stress

To further confirm participation of IbpA and IbpB in AdhE protection, we analyzed heat-in- 
A

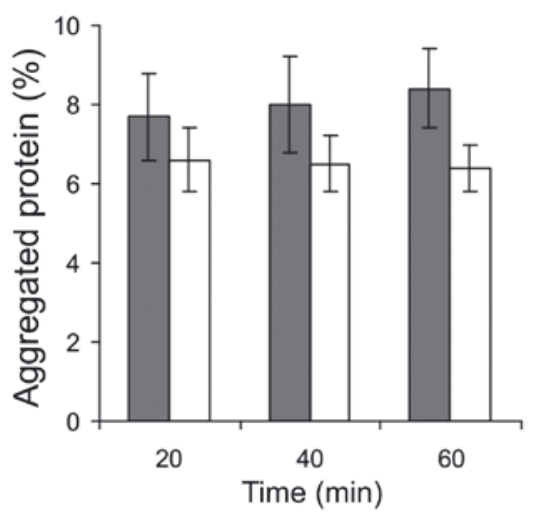

B

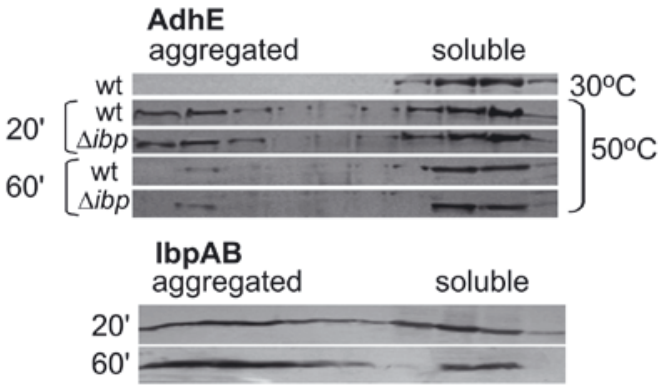

C

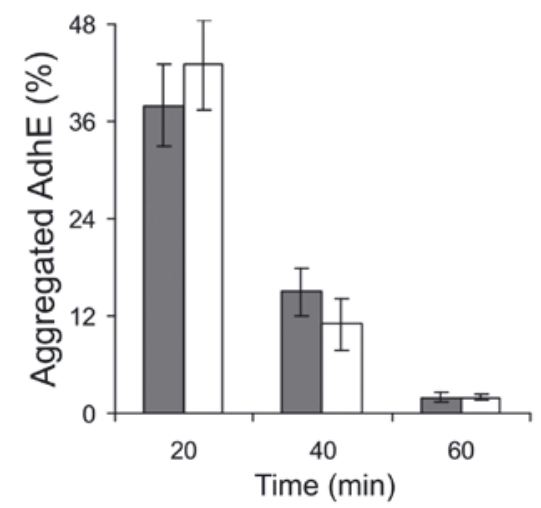

Figure 3. Aggregation of AdhE in wt and $\triangle i b p A B$ cells exposed to heat stress.

Wt and $\triangle i b p A B$ strains were grown as described in Fig. 1. To isolate aggregated proteins, the cells were harvested and fractionated by centrifugation in $30-60 \%$ sucrose gradient (see Materials and Methods) A. The amount of aggregated E. coli proteins was calculated in relation to total protein $(100 \%)$. B. AdhE, IbpA and IbpB were detected by immunoblotting in every second fraction collected from the gradient. The panel shows localization of AdhE, $\mathrm{IbpA}$ and IbpB after $20^{\prime}$ and $60^{\prime}$ at $50^{\circ} \mathrm{C}$ (wt and $\triangle i b p A B$ strains). IbpA and $\mathrm{IbpB}$ were detected in fractions obtained from wt cells $\left(20^{\prime}\right.$ and $\left.60^{\prime}\right)$. Equal volumes of each fraction were loaded on the gel. C. The amount of aggregated AdhE was estimated by densitometry in relation to the total amount of AdhE loaded on the gradient $(100 \%)$. $\mathrm{Wt}$, grey bars; $\triangle i b p A B$, white bars. Means \pm S.D. of three independent experiments are shown.

duced aggregation of AdhE by ultracentrifugation of whole cell extracts in a sucrose gradient. Since the specific AdhE activity was significantly decreased
A

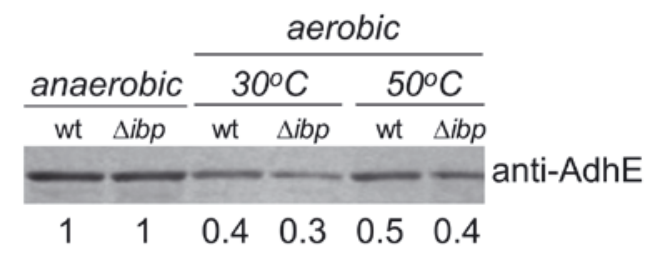

B

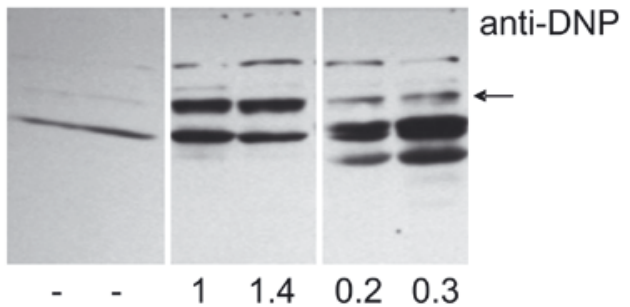

Figure 4. Carbonylation of AdhE is inhibited by IbpA and IbpB.

A. E. coli wt and $\triangle i b p A B$ strains were grown anaerobically at $30^{\circ} \mathrm{C}$ to an $\mathrm{OD}_{595}$ of 0.2 and then incubated aerobically at $30^{\circ} \mathrm{C}$ or $50^{\circ} \mathrm{C}$. After $1 \mathrm{~h}$ the bacteria were collected and submitted to DNPH derivatization. Samples containing equal amounts of protein were resolved by SDS/PAGE and analyzed by immunoblotting using anti-AdhE (A) or anti-DNP antibody (B). The levels of total AdhE (numbers below blots in panel A) and carbonylated AdhE (not shown) were estimated by densitometry. Subsequently, the relative levels of carbonylated AdhE were normalized to total AdhE amounts (numbers below blots in panel B). Representative results of three independent experiments are shown. The arrow indicates AdhE.

after heat shock in the absence of $\mathrm{IbpA}$ and $\mathrm{IbpB}$, we expected that $\triangle i b p A B$ cells would contain a higher level of aggregated AdhE than wt cells. After $20 \mathrm{~min}$ at $50^{\circ} \mathrm{C}$, about $8 \%$ and $6 \%$ of total cellular proteins was aggregated in wt and $\triangle i b p A B$ strains, respectively (Fig. $3 \mathrm{~A}$ ). The aggregates contained approx. $38 \%$ and $43 \%$ of total AdhE in wt and $\triangle i b p A B$ strains, respectively (Fig. 3B, C). According to previously published results (Kuczyńska-Wiśnik et al., 2002), the level of aggregated cellular proteins was slightly lower in $\triangle i b p A B$ than in wt cells, and did not change significantly during $1 \mathrm{~h}$ incubation at $50^{\circ} \mathrm{C}$ in the wt or in $\triangle i b p A B$ strain (Fig. $3 \mathrm{~A}$ ). However, the amount of $\mathrm{IbpA}$ and $\mathrm{IbpB}$ proteins in the aggregates increased from about $50 \%$ (at 20th min) to $70 \%$ (at 60 th $\mathrm{min}$ ) of total IbpA and IbpB level in wt cells (Fig. 3B). Interestingly, we observed disappearance of aggregated AdhE in both strains - at the end of the experiment the aggregates contained only approx. $2 \%$ of total AdhE protein (Fig. 3C). These results indicated that, the more rapid inactivation of AdhE in cells lacking IbpA and IbpB (Fig. 1B) was not accompanied by increased aggregation of AdhE (Fig. 3C). We estimated that after $20 \mathrm{~min}$ at $50^{\circ} \mathrm{C}$ inactive AdhE was mainly sequestered in the aggregates, whereas soluble fractions contained active enzyme. For example, in wt cells the specific 


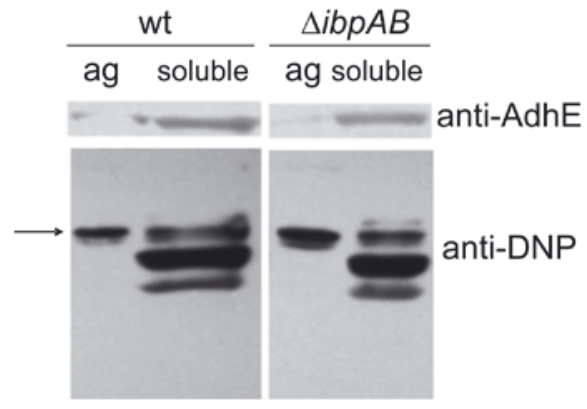

Figure 5. Carbonylation of aggregated and soluble AdhE in $E$. coli wt and $\triangle i b p A B$ cells.

The cultures were grown as described in Fig. 1. After $1 \mathrm{~h}$ incubation at $50^{\circ} \mathrm{C}$ cell extracts were prepared and subjected to fractionation (see Materials and Methods). Insoluble (ag) and soluble fractions, each containing $20 \mu \mathrm{g}$ protein, were resolved by $12 \%$ SDS/PAGE, subjected to immunodetection using anti-AdhE and anti-DNP sera. The data are representative of three experiments. The arrow indicates AdhE.

AdhE activity was decreased by approx. 39\% (Fig. 1B) and concomitantly approx. $38 \%$ of total AdhE was aggregated (Fig. 3C). At the end of the experiment $(60 \mathrm{~min})$ the vast majority of heat-inactivated enzyme in wt cells was soluble: the specific AdhE activity was reduced by approx. 55\% (Fig. 1B) but only approx. $2 \%$ of the enzyme was detected in the aggregates (Fig. 3C).

\section{IbpA and IbpB inhibit oxidation of AdhE under heat stress}

In E. coli cells exposed to heat stress in the presence of oxygen, inactivation of AdhE results from heat-denaturation and from MCO. Since we have previously found that IbpA and IbpB protect AdhE against MCO under oxidative stress induced by copper ions (Matuszewska et al., 2008), we examined the influence of IbpA and IbpB on AdhE oxidation at $50^{\circ} \mathrm{C}$. Oxidation of AdhE in wt and $\triangle i b p A B$ cells was analyzed by immunodetection of carbonyl derivatives (see Materials and Methods). The intensities of bands corresponding to carbonylated AdhE in wt and $\triangle i b p A B$ cells were comparable (Fig. $4 \mathrm{~B}$ ). However, the level of total AdhE in the $\triangle i b p A B$ mutant was lower than that in wt cells (Fig. 4A), therefore the relative levels of carbonylated AdhE at $30^{\circ} \mathrm{C}$ and $50^{\circ} \mathrm{C}$ were higher in $\triangle i b p A B$ cells. In both strains, the relative levels of oxidized AdhE at $50^{\circ} \mathrm{C}$ were apparently lower than those detected at $30^{\circ} \mathrm{C}$ (Fig. 3B). It might result from the protection of AdhE against carbonylation by IbpA, IbpB and DnaK (Echave et al., 2002; Matuszewska et al., 2008), whose overproduction was induced by heat shock. Next, we compared the degree of carbonylation of aggregated and soluble AdhE (Fig. 5). After
$60 \mathrm{~min}$ at $50^{\circ} \mathrm{C}$, both fractions, insoluble and soluble, contained carbonylated AdhE. We observed a strong signal corresponding to oxidized AdhE in the aggregates, although the fraction of aggregated proteins contained only trace amounts of AdhE (Fig. 5). Therefore, the aggregates were enriched in oxidized AdhE. In $\triangle i b p A B$ cells, the level of carbonylated AdhE detected in the aggregates was at least 2-fold higher than in the wt strain. These results confirmed that IbpA and IbpB inhibited oxidation of AdhE.

\section{DISCUSSION}

Results presented in this report provide new information on the role of IbpA and IbpB in protection of $E$. coli against heat and oxidative stress. We followed the fate of AdhE, a natural IbpA and IbpB substrate, in E. coli cells submitted to $50^{\circ} \mathrm{C}$ in the presence of oxygen. One can imagine that protein aggregates formed under heat stress are dynamic structures: unfolded proteins are constantly incorporated into aggregates but other denatured polypeptides are extracted from the aggregates and refolded or degraded. Therefore, an almost constant level of aggregated cellular proteins may be detected under certain conditions (Fig. 1A) but the composition of the aggregates can be variable. We found that heatinactivated AdhE was initially sequestered in the aggregates and almost completely removed from them during further incubation at high temperature (Fig. 3). It should be noted that newly synthesized proteins are prone to aggregation, whereas those with native conformation are resistant (Mitraki \& King, 1989). Therefore, it seems that just after the shift from $30^{\circ} \mathrm{C}$ (anaerobic conditions) to $50^{\circ} \mathrm{C}$ (aerobic conditions) newly synthesized, but not native AdhE was denatured and sequestered into aggregates. Since AdhE synthesis is inhibited after a shift from anaerobic to aerobic conditions (Clark \& Cronan, 1980) we assume that further incubation at $50^{\circ} \mathrm{C}$ $\left(40-60^{\prime}\right)$ did not cause significant incorporation of additional AdhE molecules into aggregates. We observed, however, progressive degradation (Fig. 1A) and inactivation of AdhE (Fig. 1B) which remained in a soluble form. It is tempting to speculate that during prolonged incubation at $50^{\circ} \mathrm{C}$ inactive but still soluble AdhE is immediately degraded. It is also possible that unfolded AdhE is maintained in a soluble form by molecular chaperones which are ineffective in protecting or reactivating AdhE due to the severity of the stress and overloading of the chaperone systems with unfolded substrates.

We are not able to distinguish whether aggregated AdhE was renatured or removed by proteolytic degradation. The aggregates contained very high amounts of irreversibly carbonylated AdhE when 
compared to the soluble fraction (Fig. 5). This result is consistent with the observation that misfolded proteins are more susceptible to carbonylation than their native counterparts (Nyström, 2005). It is also proposed that carbonyl groups signal that the protein is irreversibly damaged and mark the protein for degradation (Dalle-Donne et al., 2006). Therefore, we suppose that removal of aggregated AdhE relied mainly on proteolytic degradation. Consistently, aggregated non-carbonylated AdhE, which was denatured at $50^{\circ} \mathrm{C}$ under anaerobic conditions, was more stable than that denatured and aggregated in the presence of oxygen (J. Kwiatkowska, unpublished).

In cells lacking $\mathrm{IbpA}$ and $\mathrm{IbpB}$, inactivation of AdhE proceeded faster (Fig. 1B) but was not accompanied by increased aggregation of the enzyme (Fig. 3C), as could be expected from earlier studies (Kuczyńska-Wiśnik et al., 2002). Moreover, the $\triangle i b p A B$ mutation did not affect the removal of aggregated AdhE. This observation seems contradictory to previous results demonstrating that IbpA and/ or $\mathrm{IbpB}$ are necessary for efficient removal of unfolded proteins from aggregates (Kuczyńska-Wiśnik et al., 2002; Mogk et al., 2003a, Jiao et al., 2005). However, in those studies the disappearance of aggregated proteins was observed at recovery temperatures $\left(25^{\circ} \mathrm{C}, 37^{\circ} \mathrm{C}\right)$, whereas in our experiments aggregated AdhE was removed in E. coli cells exposed to $50^{\circ} \mathrm{C}$. It is possible that $\mathrm{IbpA}$ and/or $\mathrm{IbpB}$ are not required for the extraction of aggregated substrates subjected to irreversible oxidative damage and tagged for degradation. Nevertheless, IbpA and IbpB sequestered in the aggregates may cooperate with the DnaK system and facilitate refolding of aggregated but nonoxidized proteins. It is worth noting that AdhE was the only carbonylated protein detected in the aggregates (Fig. 5). Our results indicate that $\mathrm{IbpA}$ and $\mathrm{IbpB}$ protect AdhE against heat inactivation, providing that the enzyme remains soluble. We found that during prolonged heat stress the IbpA and IbpB proteins are relocated in wt cells from the soluble to insoluble fraction (Fig. 3B) and a defficiency of IbpA and/or IbpB in the soluble fraction may results in increased inactivation of AdhE.

This work provides further evidence that $\mathrm{IbpA}$ and $\mathrm{IbpB}$ protect proteins against thermal oxidation (Figs. 4 and 5). These results are consistent with previous reports demonstrating that IbpA and $\mathrm{IbpB}$ enhance E. coli resistance to superoxide stress and suppress inactivation of selected enzymes by hydrogen peroxide and potassium superoxide in vitro (Kitagawa et al., 2000; 2002). It was also found that the $\triangle i b p A B$ strain exhibits increased sensitivity to superoxide radicals generated by tellurite (Perez et al., 2007). In our previous work we demonstrated that $\mathrm{IbpA}$ and $\mathrm{IbpB}$ protect $E$. coli cells against oxidative stress induced by $\mathrm{Cu}^{2+}$ (Matuszewska et al.,
2008). The role of other Hsps under oxidative stress has also been documented. Echave and coworkers (2002) found that DnaK prevents MCO of AdhE. It was also reported that overproduction of Hsps reduced stasis-induced carbonylation of mistranslated proteins (Fredriksson et al., 2005; 2007). Cells exposed to high temperature in the presence of oxygen are also challenged by oxidative stress (Benov \& Fridovich, 1995), it is therefore reasonable that Hsps possess additional anti-oxidant activities.

\section{Acknowledgements}

We thank Professor Barbara Lipińska for discussions and critical reading of the manuscript.

This work was supported by UG grant BW/ 1460-5-0378-8 and grant 0401/P04/2005/28 from the Ministry of Science and Higher Education.

\section{REFERENCES}

Benov L, Fridovich I (1995) Superoxide dismutase protects against aerobic heat shock in Escherichia coli. J Bacteriol 177: 3344-3346.

Bradford MM (1976) A rapid and sensitive method for quantition of protein utilizing the principle of proteindye binding. Anal Biochem 72: 248-254.

Cecarini V, Gee J, Fioretti E, Amini EM, Angeletti M, Eleuteri AM, Keller JN (2007) Protein oxidation and cellular homeostasis: emphasis on metabolism. Biochim Biophys Acta 1773: 93-104.

Clark DP, Cronan JE (1980) Escherichia coli mutant with altered control of alcohol dehydrogenase and nitrate reductase. J Bacteriol 141: 177-183.

Dalle-Donne I, Aldini A, Carini M, Colombo R, Rossi R, Milzani A (2006) Protein carbonylation, cellular dysfunction, and disease progression. J Cell Mol Med 10: 389-406.

Echave P, Esparca-Ceron MA, Cabiscol E, Tamarit J, Ros J, Membrillo-Hernández J, Lin ECC (2002) DnaK dependence of mutant ethanol oxidoreductases evolved for aerobic function and protective role of the chaperone against protein oxidative damage in Escherichia coli. Proc Natl Acad Sci USA 99: 4626-4631.

Eraso JM, Weinstock GM (1992) Anaerobic control of colicin E1 production. J Bacteriol 174: 5101-5109.

Fredriksson A, Ballesteros M, Dukan S, Nyström T (2005) Defence against protein carbonylation by DnaK/DnaJ and proteases of the heat shock regulon. J Bacteriol 187: 4207-4213.

Fredriksson A, Ballesteros M, Dukan S, Nyström T (2007) Induction of the heat shock regulon in response to increased mistranslation requires oxidative modification of the malfolded proteins. Mol Microbiol 59: 350-359.

Haslbeck M, Franzmann T, Weinfurtner D, Buchner J (2005) Some like it hot: the structure and function of small heat shock proteins. Nature Struct Mol Biol 12: 842-846.

Jiao W, Li P, Zhang J, Zhang H, Chang Z (2005) Small heat-shock proteins function in the insoluble protein complex. Biochem Biophys Res Commun 335: 227-231.

Kitagawa M, Miyakawa M, Matsumura Y, Tsuchido T (2000) Small heat shock proteins, IbpA and IbpB, are 
involved in resistances to heat and superoxide stress in Escherichia coli. FEMS Microbiol Lett 184: 165-171.

Kitagawa M, Miyakawa M, Matsumura Y, Tsuchido T (2002) Escherichia coli small heat shock proteins, IbpA and $\mathrm{IbpB}$, protect enzymes from inactivation by heat and oxidant. Eur J Biochem 269: 2907-2917.

Kuczyńska-Wiśnik D, Kędzierska S, Matuszewska E, Lund P, Taylor A, Lipińska B, Laskowska E (2002) The Escherichia coli small heat-shock proteins IbpA and IbpB prevent the aggregation of endogenous proteins denatured in vivo during extreme heat shock. Microbiology 148: 1757-1765.

Laskowska E, Wawrzynów A, Taylor A (1996) IbpA and $\mathrm{IbpB}$, the new heat shock proteins, bind to endogenous Escherichia coli proteins aggregated intracellularly by heat shock. Biochimie 78: 117-122.

Matayoshi S, Oda H, Sarwar G (1989) Relationship between the production of spirosomes and anaerobic glycolysis activity in Escherichia coli B. J Gen Microbiol 135: 525-529.

Matuszewska M, Kuczyńska-Wiśnik D, Laskowska E, Liberek K (2005) The small heat shock protein IbpA from Escherichia coli cooperates with $\mathrm{IbpB}$ in stabilization of thermally aggregated proteins in a disaggregation competent state. J Biol Chem 280: 12292-12298.

Matuszewska E, Kwiatkowska J, Kuczyńska-Wiśnik D, Laskowska E (2008) Escherichia coli heat-shock proteins $\mathrm{IbpA} / \mathrm{B}$ are involved in resistance to oxidative stress induced by copper. Microbiology 154: 1739-1747.

Membrillo-Hernández J, Echave P, Cabiscol E, Tamarit J, Ros J, Lin ECC (2000) Evolution of the adhE gene product of Escherichia coli from a functional reductase to a dehydrogenase. J Biol Chem 275: 33869-33875.
Mitraki A, King J (1989) Protein folding intermediates and inclusion body formation. Biotechnology 7: 690-697.

Mogk A, Deuerling E, Vorderwülbecke S, Vierling E, Bukau B (2003a) Small heat shock proteins, ClpB and the DnaK system form a functional triade in reversing protein aggregation. Mol Microbiol 50: 585-595.

Mogk A, Schlieker C, Friedrich KL, Schönfeld HJ, Vierling E, Bukau B (2003b) Refolding of substrates bound to small Hsps relies on a disaggregation reaction mediated most efficiently by ClpB/DnaK. J Biol Chem 278: 31033-31042.

Nakamoto H, Vigh L (2007) The small heat shock proteins and their clients. Cell Mol Life Sci 64: 294-306.

Nyström T (2005) Role of oxidative carbonylation in protein quality control and senescence, EMBO J 24: 13111317.

Perez JM, Calderon IL, Arenas FA, Fuentes DE, Pradenas GA, Fuentes EL, Sandoval JM, Castro ME, Elias AO, Vasques CC (2007) Bacterial toxicity of potassium tellurite: unveiling an ancient enigma. PLOS ONE 2: e211.

Sambrook J, Fritsh EF, Maniatis F (1989) Molecular Cloning: A Laboratory Manual, 2nd ed. Cold Spring Harbor Laboratory Press, New York.

Sun Y, MacRae TH (2005) The small heat shock proteins and their role in human disease. FEBS J 272: 26132627.

Veinger L, Diamant S, Buchner J, Goloubinoff P (1998) The small heat-shock protein IbpB from Escherichia coli stabilizes stress-denatured proteins for subsequent refolding by a multichaperone network. J Biol Chem 273: 11032-11037. 